\title{
Problems Existing in the Process of Clinical Medicine Undergraduate Practice and Coping Strategies
}

\author{
Jihua Wei ${ }^{1 *}$, Haidong Zhou ${ }^{2 \#, ~ Q u n q i a n g ~ L u o ~}{ }^{*}$, Dinggui Lu${ }^{1}$, Jianchu Wang1, Dianbo Yu1, \\ Qisheng Luo' ${ }^{1}$ Zaiyong Li², Kangqi Xie ${ }^{2}$, Fuqiang Luo ${ }^{2}$, Changtai Luo \\ ${ }^{1}$ Youjiang Medical University for Nationality, Baise, China \\ ${ }^{2}$ The Affiliated Hospital of Youjiang Medical University for Nationality, Baise, China \\ Email: *1261290953@qq.com
}

How to cite this paper: Wei, J. H., Zhou, H. D., Luo, Q. Q., Lu, D. G., Wang, J. C., Yu, D. B., Luo, Q. S., Li, Z. Y., Xie, K. Q., Luo, F. Q., \& Luo, C. T. (2021). Problems Existing in the Process of Clinical Medicine Undergraduate Practice and Coping Strategies. Creative Education, 12, 2090-2097. https://doi.org/10.4236/ce.2021.129160

Received: August 19, 2021

Accepted: September 13, 2021

Published: September 16, 2021

Copyright $\odot 2021$ by author(s) and Scientific Research Publishing Inc. This work is licensed under the Creative Commons Attribution International License (CC BY 4.0).

http://creativecommons.org/licenses/by/4.0/

\begin{abstract}
The effect of clinical practice directly affects the clinical ability and professional quality of graduates, lack of interest in practice, lack of doctor-patient communication skills and conflict with other clinical training doctors are common problems in current practice. This article through to the clinical medical undergraduate interns in practice there is lack of interest, in the process of doctor-patient communication skills and conflict with other clinical training for doctors and other issues were discussed, and through the reform of teaching methods, strengthen the teaching supervision and organize training of doctor-patient communication, in order to improve the clinical interns learning autonomy, strengthen the doctor-patient communication skills, to further improve the quality of medical personnel training to provide help.
\end{abstract}

\section{Keywords}

Medical Students, The Internship, Interest, Doctor-Patient Communication

\section{Background}

In recent years, with the continuous improvement of people's living standards, knowledge and cultural level and the continuous improvement of the medical system, the number of outpatient and inpatient patients has increased greatly. In this context, many medical colleges and universities have expanded the enrollment of clinical medical students, and more and more talents have poured into

${ }^{*}$ These authors contributed equally to this study.

"Corresponding author. 
the medical industry. In China, hospitals with internship sites are generally affiliated hospitals of medical schools, which leads to a large number of medical students piled up in the same hospital, and many internship problems follow one after another, mainly manifested in the following aspects: 1) Decreased interest in internship, improper teaching supervision; 2) Doctor-patient communication skills are weak, lack of clinical exercise opportunities; 3) Conflicts with other physicians participating in clinical training. The purpose of this paper is to discuss the problems of five-year undergraduate clinical interns and propose solutions to further improve the quality of clinical medical students practice.

\section{Problems Existing in the Process of Clinical Medicine Undergraduate Practice}

1) Clinical practice is an important way to cultivate hospital talents, which is the transformation from clinical medical students to clinicians, and also an important year to put the knowledge from textbooks into practice. During the year, not only requires to master each department common disease symptoms, diagnosis, treatment and so on, also require interns to master all kinds of clinical skills, in some professional strong departments such as bone surgery, with diseases, and more professional, more great operation difficulty, clinically appear a lot of new technology, new materials, new equipment, knowledge update quickly, The internship time for interns in these departments is only 2 weeks, so it is difficult to master the basic knowledge of this major. Moreover, due to the lack of teacher resources, the diagnosis and treatment of various diseases cannot be introduced in detail as in class, resulting in many interns are unable to master the diagnosis and treatment of common diseases in corresponding departments. Secondly, a survey found that $32 \%$ of medical students reported that clinical teaching teachers did not pay enough attention to teaching (Guo, Gao, \& Chen, 2019), and only $29 \%$ of teaching teachers were able to provide students with practical operation opportunities in a planned way (Song, Guo, Zhang et al. 2019). As a result, the interest in internship decreases, and it is difficult to obtain effective harvest within the limited internship time (Zhou, 2021).

For interns, the initial internship life is of great interest to them. However, since many students can not well grasp the diseases of various systems during the undergraduate period, and the busy work during the internship, many students have no intention to review the knowledge learned during the undergraduate period, which leads to the forgetting of many knowledge points. In neurology, cardiology, for example, need very solid professional knowledge, teaching the teacher often don't have much time to explain the disease mechanism and intern, a lot of knowledge teaching teacher is all about, so I asked the students a solid foundation, but most of the students are unable to reach the threshold, resulting in a loss to the enthusiasm of practice (Qiao, Wang, Huang et al., 2017); In addition, under the impact of the new champions league outbreak, increasing demand for medical talent, medical industry big influx of talent, tal- 
ent competition is intense, the hospital for medical graduate degree requirements become higher, many graduates to choose one's deceased father grind or test abundantly, therefore, they often pay a lot of time to prepare for and practice for them to become less important than it Moreover, intern is by the unified management of hospital management section of teaching, for those interns with a negative attitude, teaching teachers lack of dispose of, only for oral education, if want to undertake to the student, refer to report, but work in a line of teaching teachers refer to teachers lack of communication, many problems cannot be reflected in the teaching management department, This has led to an increasingly lazy attitude towards internships. In addition, some students believe that they will not be engaged in the current internship in the future, and that the knowledge they have learned is not useful for their future work. They do not pay attention to the content of the internship, and even do bad behaviors such as leaving early and avoiding the internship, which leads to the poor quality of the internship (Jiang \& Pu, 2020).

2) Doctor-patient communication skills are weak, lack of clinical exercise opportunities

Modern medicine has been transformed into a society-psychology-biomedical model, which means that medical students need not only a solid foundation of clinical knowledge, but also a high level of medical humanities. Studies have shown (Liu, Rohrer et al., 2015) that $98.47 \%$ of hospitals are troubled by medical disputes, $70 \%$ of which are caused by poor doctor-patient communication. Effective doctor-patient communication is critical to quality care, improving patient satisfaction, patient recall and understanding, adherence to treatment, and outcomes, including symptom reduction. In recent years, all kinds of malignant medical injury incidents on the media emerge in endlessly, bringing great harm to both doctors and patients. There are some reasons for the occurrence of malignant medical injury events, many of which are caused by the communication problems between doctors and patients. This requires us to continuously improve the communication skills between doctors and patients and reduce the occurrence of conflicts between doctors and patients. The internship stage is the initial stage for interns to contact with real patients. It is an important period for interns to develop good doctor-patient communication skills in this stage. In recent years, however, because of the doctor-patient relationship is more and more nervous, a lot of teaching teachers think intern humanities cultivated manners, weak communication skills and basic knowledge is not solid enough ( $\mathrm{Lu}$ et al., 2020), is not up to this important work of doctor-patient communication, and lack of exercise, lead to communication skill level is low, lack of confidence when they face the patient, a lot of times chose to escape.

3) Conflicts with other physicians in clinical training

With medical school recruit students number increases year by year and the standardization of training (hereinafter referred to as the "rules" culture) and professional master graduate student (hereinafter referred to as the "master") the 
establishment of the relevant system, a large number of talents into the health care industry, and conditional receiving gauge Pearson, professional master, graduate students, most of the intern hospital for medical school affiliated hospital, limited teaching resources, concentration, This leads to the concentration of a large number of professional master's students, scheduled students, advanced students and interns in a certain department, resulting in a shortage of internship resources, including patients and teachers. In addition, doctors working in large internship hospitals not only have hospital diagnosis and treatment tasks, but also scientific research, teaching tasks, they do not have enough energy to teach interns. Taking the affiliated hospital of Youjiang Nationalities Hospital as an example, the medical team of a department is usually composed of doctors, scheduled students, professional master's students, advanced students and interns. In this team, the intern's clinical knowledge reserve is undoubtedly at the lowest level in the team. The teachers prefer to give some clinical exercise opportunities to professional master's students, scheduled students and advanced students who have clinical practice experience. Therefore, there are fewer opportunities for interns to exercise. Although the domestic many medical school will set up skill training center for students to practice using, but most of the hospital resources will be to "rules" culture, "master's" tilt, let them have more time to prepare skill examination of medical practitioners, has caused many to intern training blur, intern skills practice time shortened, practice effect is self-evident (He \& Zhang, 2021).

\section{Coping Strategies}

\subsection{Enhance Students' Autonomy and Strengthen Teaching Supervision}

Interns are the backup force for clinicians, and the effect of internship affects when they can transform into real clinicians. Internship life is not as comfortable as school life, because there is no teacher to teach intensively in this year, and interns need to take the initiative to learn. In hospitals, teachers with high professional titles are busy with surgery, while teachers with low professional titles are busy with basic hospital work, scientific research and teaching tasks, so they have no time to teach interns actively. If interns practice with a muddle-through attitude, it will undoubtedly reduce their interest in practice. How to improve interns' interest in practice has become an important problem for practice teaching. This requires teachers to use certain teaching skills; First of all, the department arranged special practice teaching teachers to reduce the basic work of practice teaching teachers in the hospital, and shifted their work focus to practice teaching, so that they should have enough patience and care in the teaching process. As internship is the first step for graduates to step into the society, it is the transition stage from school to society. At this time, their minds are not mature and their ability to resist pressure is poor, so they need to be guided step by step by teachers to improve their cognition and interest in internship. Secondly, 
when interns complete clinical tasks, the instructor should give appropriate recognition. An encouraging word and a positive look from the instructor can enhance the self-confidence of interns and put them into work more seriously ( $\mathrm{Li}$, Sun, Gao et al., 2019). Moreover, because of medical knowledge update faster, a lot of clinical interns will find that the actual diagnosis and textbook has a large discrepancy between what they have learned, let them skeptical of what they have learned in school knowledge, lack of confidence, this requires in clinical teaching, teaching teachers guide interns through literature, improve the ability of autonomous learning, cultivate interns ability of combining theory and practice, Training interns' clinical thinking (Cao, 2020); And by selecting a typical patient, the characteristics in real cases, with the most acceptable way to teach interns, so we can make the interns have a sense of accomplishment (Zhang, Wang, \& Liu, 2019), through simple cases, you can do all students can participate in, to enrich the students' ability of clinical thinking and communication (Huang \& Zheng, 2010), while enrich their theoretical knowledge, It also increases their confidence, which naturally increases their interest in the internship.

For students with negative attitudes, teachers should communicate with interns in a timely manner to make them realize that clinical practice is the basic stage for every doctor, and change their attitude of "I will not engage in the current internship work and do not need to study hard". In order to improve their internship enthusiasm, an important method is to give them more opportunities to participate in the diagnosis and treatment. Under the condition of ensuring patient safety and not violating the principles of medical safety, interns should be given appropriate opportunities to do things by themselves, and encouraged to complete some basic clinical skills independently. And after the completion of the operation, the interns briefed the operation experience, and made evaluation, to strengthen their memory. For the students with poor hands-on ability to repeatedly patient guidance, put an end to impatience, negative emotions. For interns with strong operational ability, more difficult operational training should be given appropriately (Xue, 2016). For those interns who avoid the internship, the teachers should pay attention to them in time, understand whether the students are troubled in life or study, provide targeted psychological counseling, and report to the teaching Department in time to strengthen the management of the interns. It is believed that the above two methods will enhance the enthusiasm and self-discipline of the interns, and avoid the negative emotions of the interns, or even the behaviors of escaping the internship.

\subsection{Strengthen Doctor-Patient Communication Skills, Organize Doctor-Patient Communication Training}

In the traditional medical teaching system, most doctors attach importance to the teaching of theories and skills, but ignore the training of communication skills. Many doctors can use their professional knowledge to solve the problems 
of patients, but they often lack humanistic care, which is an important factor in the tension between doctors and patients. More and more hospital administrators are also aware of this point and begin to strengthen the doctor-patient communication training for medical workers. How to strengthen the communication skills during the internship has become a hot issue in the current internship (Guo \& Jian, 2021). Traditional way of teaching is the interns with behind teaching teachers to participate in rounds, accumulating clinical communication skills, but this way has its limitations, whether explain the illness, treatment, all need to have a deeper theoretical basis and communication skills, or it will lead to don't understand or worry too much about the patient, can't cooperate with the doctor's diagnosis and treatment, This leads interns to be strangely fearful of such communication. In order to improve this situation, we mainly through the following two modes of reform: 1) teaching teachers to interns, interns alone management of 1 to 2 beds, independent communication of the condition, teaching teachers to guide beside. After the communication, the interns should summarize the deficiencies in the communication with patients, and guide the interns to strengthen their further understanding of the disease through literature review, so as to cultivate correct clinical thinking and strengthen doctorpatient communication skills (Yu \& Zhang, 2019). By directly participating in the management of patients, interns can contact the whole content of clinical work and truly experience the communication skills with patients, which is of great significance for cultivating their independent clinical diagnosis and treatment skills and doctor-patient communication skills (Qian, Yu, Ji et al., 2020). 2) The hospital will organize doctor-patient communication training irregularly to strengthen the communication skills of interns. Good doctor-patient communication can promote the diagnosis and treatment of diseases, increase patients' compliance with doctors' diagnosis and treatment plans, increase patients' satisfaction with doctors and hospitals, and ease the tension of doctor-patient relationship to the greatest extent. In addition, we can organize a doctor-patient communication contest to improve the attention of interns on doctor-patient communication. All interns are required to participate in the contest, and the scoring standards are formulated. Experienced and senior doctors are the judges, and the results of the contest are taken as a reference for the evaluation of scholarships. 3) Simulated patient (SP) model training: Previous studies (Jabeen, 2013) found that the collection of medical records of real patients and SP patients was not meaningful, and the interview results of students showed that $97.9 \%$ of students agreed to use simulated patients to evaluate communication skills. 64.9\% thought there was no difference between real patients and simulated patients. In this regard, we propose to replace the real patients with SP patients. On the one hand, it can reduce the psychological pressure of the interns facing the patients, let the interns give full play to their communication skills with the patients, and enhance their doctor-patient communication skills. On the other hand, it can reduce patients' contempt for interns and reduce medical disputes 
to a certain extent.

\section{Conclusion}

With the development of medical cause and the continuous reform of medical education policy, clinical undergraduate practice teaching is also changing; there are still many problems to be solved in the practice process. How to improve interns' interest in practice, enhance doctor-patient communication skills and improve the effect of practice is still a hot topic in the field of medical education. Studies have shown that (Wang, Cui, Lin et al. 2020), the superior affirmation and scene simulation can significantly improve students' learning initiative and enthusiasm of internship and interest score more superior to the traditional teaching method, through the reform of teaching of the teacher's teaching method, strengthen the teaching teachers focus on interns and affirmation, improve the intern's self-confidence, to improve interns by interest in the internship; On the other hand (Yin, Yao, Wang et al. 2016), communication skills are usually not established in a short period of time, and it must be honed over a long period of time to let interns manage patients independently, which can not only let them know the diagnosis and treatment process of the disease, but also exercise their communication skills. The way of organizing doctor-patient communication competition can arouse the "competitive spirit" of interns, and the learning effect can be twice the result with half the effort; And using SP patients to simulate real patients, so that students have more extensive expression space, and teachers can also point out the shortcomings on the spot, more impressive. In this paper, the effect of practice becomes better by reforming traditional teaching methods, enhancing interns' interest in practice and communication skills, and providing help for further improving the quality of medical talent training. However, the specific implementation methods need to be considered by the majority of medical educators.

\section{Funding}

The First Batch of High-level Talent Scientific Research Projects of the Affiliated Hospital of Youjiang Medical University for Nationalities in 2019 (Contract No. R20196321). Guangxi Higher education undergraduate teaching reform project (\#2021JGA278, \#2021JGB301).

\section{Conflicts of Interest}

The authors declare no conflicts of interest regarding the publication of this paper.

\section{References}

Cao, X. F. (2020). Four Tetralogy of Learning Interest of Clinical Interns. Continuing Medical Education, No. 12, 61-62.

Guo, H., Gao, X. Y., \& Chen, X. Y. (2019). Discussion on the Reasons and Countermeasures of Influencing the Quality of Clinical Practice of Medical Students. Sino-Foreign 
Exchange, No. 19, 26-35.

Guo, W. N., \& Jian, Z. (2021). Application of Doctor-Patient Communication Training in Clinical Teaching of Dermatology. Medical Education Research, and Practice, No. 2, 330-334.

He, W., \& Zhang, M. (2021). Difficulties and Strategies in Clinical Practice Skills Teaching for medical students. China Continuing Medical Education, No. 11, 91-95.

Huang, W., \& Zheng, J. (2010). Application and Experience of CBL Teaching Model in Clinical Teaching of Neurology. Chongqing Medical, 39, 501-503.

Jabeen, D. (2013). Use of Simulated Patients for Assessment of Communication Skills in Undergraduate Medical Education in Obstetrics and Gynaecology. Journal of the College of Physicians and Surgeons-Pakistan, 23, 16-19.

Jiang, Z., \& Pu, L. (2020). Problems and Countermeasures in Clinical Medicine Undergraduate Practice. Education Modernization, No. 7, 189-191.

Li, P. Z., Sun, X. L., \& Gao, X. et al. (2019). The Practice of Engineering Thinking Training in Clinical Medicine Teaching for Undergraduate Students. Basic Medical Education, No. 7, 551-552.

Liu, X., Rohrer, W., Luo, A., Fang, Z., He, T. H., \& Xie, W. (2015). Doctor-Patient Communication Skills Training in Mainland China: A Systematic Review of the Literature. Patient Education and Counseling, 98, 3-14. https://doi.org/10.1016/j.pec.2014.09.012

Lu, S. M., Du, J. L., Yi, G. L. et al. (2020). Investigation on the Status Quo of Clinical Internship and practice in Medical Colleges. Continuing Medical Education, No. 4, 39-41.

Qian, M. P., Yu, X. J., Ji, G. Y. et al. (2020). Research on the Assessment Method of Doctor-Patient Communication Teaching Practice Ability. Hainan Medical Science, 21, 2840-2842.

Qiao, R., Wang, S. H., Huang, L. H. et al. (2017). Research on Problems and Countermeasures in Undergraduate Graduation Practice after the Implementation of Credit System. Journal of Baotou Medical College, No. 4, 131-133.

Song, D. R., Guo, J., Zhang, W. et al. (2019). A Multi-Dimensional Survey of Medical Students' Clinical Practice Status and Satisfaction. Chinese Journal of Medical Education, 39, 197-202.

Wang, Y., Cui, X. Q., Lin, Y. X. et al. (2020). Effects of Multiple Scenario Simulation Teaching on Nursing Students' Interest in Traditional Chinese Medicine. Nursing Technology and Satisfaction of Teaching Model, 21, 146-150.

Xue, J. (2016). Explore the Factors Affecting the Quality of Medical Students' Practice and Improvement Measures. Research in Curriculum Education, 24, 188-189.

Yin, K., Yao, F. L., Wang, Y. et al. (2016). Current Situation Analysis and Countermeasures of Doctor-Patient Relationship. Chinese Health Quality Management, No. 3, 63-66.

Yu, Q. X., \& Zhang, X. P. (2019). Diagnosis Information Exchange Mediates the Effect of Patient Initiative on Doctors' Treatment Recommendations in Online Doctor-Patient Communication: A Cross-Sectional Study. The Lancet, 394, S50.

Zhang, Y. R., Wang, L., \& Liu, D.H. (2019). The Application Effect of Mini-CEX Teaching Method in the Training of Nurses in Neurology Department under the Mode of Medical Union. Contemporary Nurse (Mid-Day), No. 9, 160-163.

Zhou, Z. T. (2021). The Reform Strategy of Practice Mode in Orthopedic Clinical Practice. Journal of Aerospace Medicine, No. 3, 333-336. 